\title{
Cone penetration test-based load-transfer formulations for driven piles in sand
}

\author{
B. M. LEHANE*, L. LI† and E. J. BITTAR*
}

\begin{abstract}
This paper presents the development of load-transfer curves that can be used to estimate the displacement under axial load of driven piles in sand. The maximum skin friction and end-bearing stress are obtained from new ISO 19901-4 cone penetration test (CPT)-based formulations, which were calibrated using a high-quality database of static pile load tests compiled for this purpose. The load-displacement responses measured in the 71 static load tests in this database are used to derive CPT-based non-linear load-transfer curves. It is shown that good estimations of pile displacements can be obtained using CPT data and the normalised formats of shaft and base load-transfer functions provided in the American Petroleum Institute and ISO 19901-4 recommendations.
\end{abstract}

KEYWORDS: piles \& piling; sands; settlement

Published with permission by the ICE under the CC-BY 4.0 license. (http://creativecommons.org/licenses/by/4.0/)

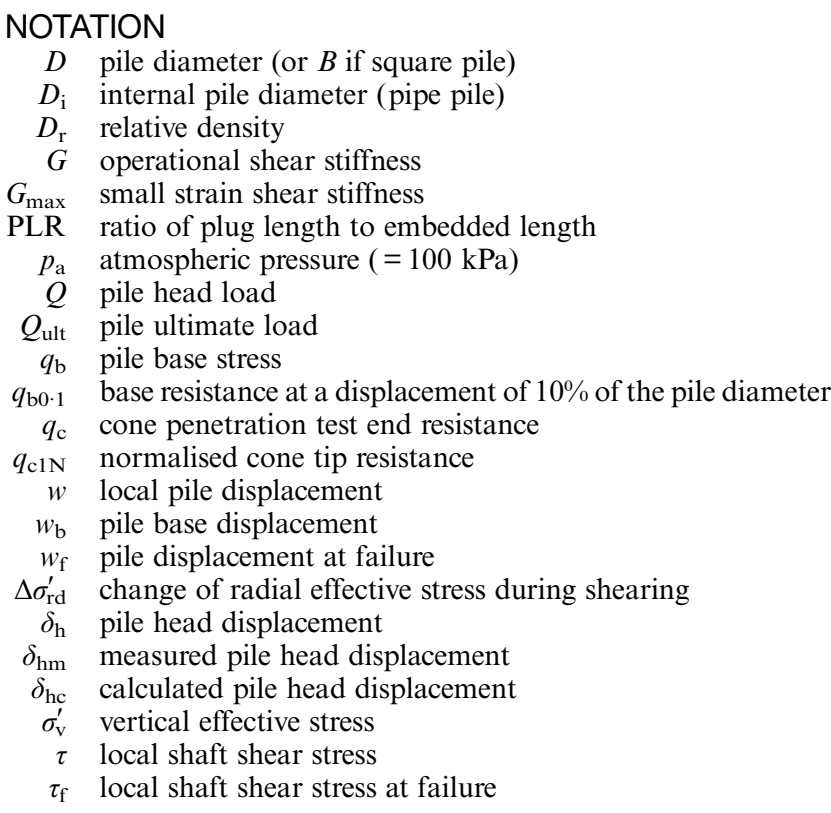

\section{INTRODUCTION}

A joint industry project (JIP) was set up in 2013 by the Norwegian Geotechnical Institute (NGI) to examine the reliability of a range of existing methods employed for evaluation of the axial capacity of driven piles in sand. To assist with this aim, the University of Western Australia (UWA) together with NGI compiled a database of highquality pile load tests in sand and clay, which is now referred to as the 'Unified' database (Lehane et al., 2017). Input into the selection of an agreed set of high-quality tests for this database

Manuscript received 20 July 2020; first decision 29 October 2020; accepted 2 November 2020.

Published online at www.geotechniqueletters.com on 12 July 2020.

*School of Engineering, The University of Western Australia, Australia.

†Faculty of Engineering, China University of Geosciences (Wuhan), China. was provided by representatives from Imperial College London, Fugro BV Ltd, NGI and UWA. Full details of the database are provided in Lehane et al. (2017), which also examines the ability of existing cone penetration test (CPT) methods to predict pile capacity. On completion of this work and motivated by the wish to achieve consensus among proponents of these CPT methods, a new JIP was formed with the objective of using this database to develop a CPT method that would supersede the existing CPT methods used to predict axial capacity of piles in sand and clay (Nadim et al., 2020). The new 'unified' CPT method for piles in sand is described by Lehane et al. (2020) and replaces previous recommendations for axial capacity estimation in ISO 19901-4 (ISO, 2020).

This paper is an extension of the research on axial pile capacities in sand and uses the 'unified' database of load-displacement curves for calibration of CPT-based load-transfer curves that can be used to estimate the displacement under axial load of driven piles in sand. This database comprises 71 pile tests with the range of pile diameters, pile lengths, CPT end resistances $\left(q_{\mathrm{c}}\right)$ and set-up times shown in Fig. 1. Further information relating to the pile end condition, pile shape, loading direction and pile material is provided in Table 1 . The transfer curves derived are aimed to allow reasonable estimates of pile displacements at typical working loads when the applied load $(Q)$ is less than about half of the ultimate capacity $\left(Q_{\mathrm{ult}}\right)$ - that is the global factor of safety on ultimate shaft friction is about $2 \cdot 0$.

\section{Unified method for calculation of axial capacity}

The derivation of load-transfer curves requires definition of the ultimate shaft friction that can develop at any location on the pile shaft $\left(\tau_{\mathrm{f}}\right)$ and the ultimate end-bearing stress acting over the full pile base area at a displacement of $10 \%$ of the pile diameter $\left(q_{\mathrm{b} 0 \cdot 1}\right)$. The new unified CPT method, which is described in full by Lehane et al. (2020), allows derivation of these parameters using the formulations provided in Table 2 and the measured $q_{\mathrm{c}}$ profiles. The basis of the formulation employed for $\tau_{\mathrm{f}}$, as evident from multiple instrumented pile tests, is the direct proportional relationship with $q_{\mathrm{c}}$ of the radial effective stress acting on a pile shaft after installation. 

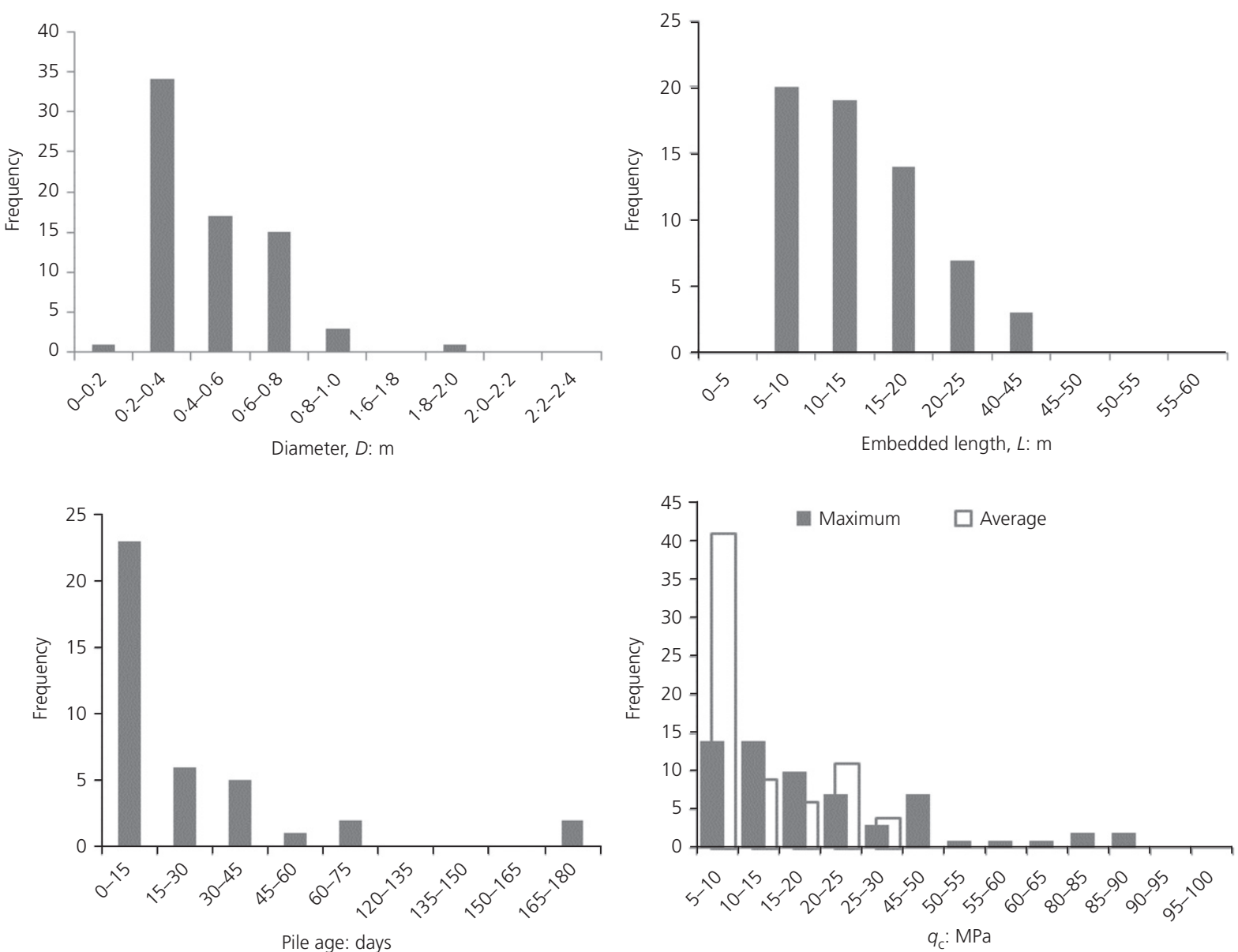

Fig. 1. Pile diameters, pile lengths, set-up time sand average $q_{\mathrm{c}}$ values in the 'unified database' for driven piles in sand

Table 1. Characteristics of the unified database of driven piles in sand

\begin{tabular}{|c|c|c|c|}
\hline \multirow[t]{2}{*}{ Description } & \multicolumn{2}{|c|}{ Number of piles } & \multirow[t]{2}{*}{ All } \\
\hline & Closed & Open & \\
\hline \multicolumn{4}{|l|}{ Material } \\
\hline Steel & 20 & 25 & 45 \\
\hline Concrete & 22 & 4 & 26 \\
\hline \multicolumn{4}{|l|}{ Shape } \\
\hline Circular & 31 & 29 & 60 \\
\hline Square (and others) & 11 & 0 & 11 \\
\hline \multicolumn{4}{|l|}{ Loading } \\
\hline Compression & 31 (CEC) & 17 (OEC) & 48 \\
\hline \multicolumn{4}{|l|}{ Direction } \\
\hline Tension & 11 (CET) & 12 (OET) & 23 \\
\hline Total & 42 & 29 & 71 \\
\hline
\end{tabular}

CEC, closed-ended pile tested in compression; CET, closed-ended piles tested in tension; OEC, open-ended pile tested in compression; OET, open-ended pile tested in tension.

Table 2. Unified CPT method for determination of $\tau_{\mathrm{f}}$ and $q_{\mathrm{b} 0 \cdot 1}$

$$
\begin{aligned}
& \tau_{\mathrm{f}}=\left(f_{\mathrm{t}} / f_{\mathrm{c}}\right)\left(\sigma_{\mathrm{rc}}^{\prime}+\Delta \sigma_{\mathrm{rd}}^{\prime}\right) \tan 29^{\circ} \\
& \sigma_{\mathrm{rc}}^{\prime}=\left(q_{\mathrm{c}} / 44\right) A_{\mathrm{re}}^{0.3} \quad[\operatorname{Max}[1,(h / D)]]^{-0.4} \\
& \Delta \sigma_{\mathrm{rd}}^{\prime}=\left(\frac{q_{\mathrm{c}}}{10}\right)\left(\frac{q_{\mathrm{c}}}{\sigma_{\mathrm{v}}^{\prime}}\right)^{-0.33}\left(\frac{d_{\mathrm{CPT}}}{D}\right) \\
& q_{\mathrm{b} 0 \cdot 1}=\left[0 \cdot 12+0 \cdot 38 A_{\mathrm{re}}\right] q_{\mathrm{p}} \\
& A_{\mathrm{re}}=1-\operatorname{PLR}\left(D_{\mathrm{i}} / D\right)^{2} \\
& \text { PLR } \approx \tanh \left[0 \cdot 3\left(D_{\mathrm{i}} / d_{\mathrm{CPT}}\right)^{0.5}\right]
\end{aligned}
$$$$
\begin{aligned}
& f_{\mathrm{t}} / f_{\mathrm{c}}=1 \cdot 0 \text { in compression and } 0.75 \text { in tension } \\
& Q_{\text {base }}=q_{\mathrm{b} 0 \cdot 1}\left(\pi D^{2} / 4\right) \\
& A_{\mathrm{re}}=1 \text { for closed-ended pile } \\
& d_{\mathrm{CPT}}=35.7 \mathrm{~mm}
\end{aligned}
$$

$q_{\mathrm{p}}$, end bearing mobilised at large displacements at the level of the pile tip by a pile with a diameter of $D_{\mathrm{eq}}\left(=D A_{\mathrm{re}}^{0.5}\right)$. In relatively homogeneous sands, $q_{\mathrm{p}}$ can be taken as the average $q_{\mathrm{c}}$ value within a zone $1.5 \mathrm{D}$ above and below the pile tip. In more variable strata, designers can assume $q_{\mathrm{p}}=1 \cdot 2 q_{\mathrm{c}, \text { Dutch }}$ (Schmertmann, 1978) or adopt the technique proposed by Boulanger \& DeJong (2018).

Source: Lehane et al. (2020) 
Additional factors known to influence shaft friction are also incorporated, namely $(a)$ the degree of soil displacement (plugging) during installation, $(b)$ the relative pile tip depth, $(c)$ the sand-pile interface friction angle, $(d)$ changes in radial stress during loading and $(e)$ the loading direction (tension or compression). The formulation for $q_{\mathrm{b} 0 \cdot 1}$ is also based on a direct relationship with $q_{\mathrm{c}}$ and allows for the important influence of plugging during installation of pipe piles. The equations for shaft friction (Table 2) allow for a reduction in the relative influence of dilation (captured by the $\Delta \sigma_{\text {rd }}^{\prime}$ term) and plugging (by way of the effective area ratio term, $\left.A_{\text {re }}\right)$ as the pile diameter increases, hence enabling safe extrapolation from the database piles (the majority of which had diameters less than $800 \mathrm{~mm}$ )

\section{Load-transfer functions}

The load-transfer method, first proposed by Coyle \& Reese (1966), is a popular means of estimating axial pile displacement. This method combines the axial stiffness of multiple pile elements with associated non-linear load-transfer functions (or springs) to represent the variation of shaft friction $(\tau)$ with local displacement $(w)$ and the variation of pile base load $\left(q_{\mathrm{b}}\right)$ with base displacement $\left(w_{\mathrm{b}}\right)$

\section{Shaft load-transfer function $(\tau-\mathrm{w})$}

The $\tau-w$ spring, which is more commonly referred to as a $t-z$ curve, in any given soil horizon depends on the specific non-linear shear stiffness-shear strain relationships of elements of soil extending radially from the pile within the complex stress field set up following pile installation. In view of these complexities, a practical approach commonly employed is to presume either a power-law, hyperbolic or parabolic variation of $\tau$ with $w$ and to define a displacement $\left(w_{\mathrm{f}}\right)$ at which $\tau$ attains its maximum value of $\tau_{\mathrm{f}}$. Fellenius (2018) reviews a variety of functions proposed for these load-transfer curves such as the ratio function of Gwizdala (1996), the hyperbolic function of Chin (1970) and the exponential relationship of van der Veen (1953). The parabolic form of the normalised $\tau-w$ curve, proposed by Randolph (2003), is employed in this study and is expressed as

$$
\frac{\tau}{\tau_{\mathrm{f}}}=\left(\frac{G}{\tau_{\mathrm{f}}}\right)\left(\frac{w}{2 D}\right)\left[1-\frac{w}{2 w_{\mathrm{f}}}\right] \text { where } \frac{w_{\mathrm{f}}}{D}=\frac{4}{\left(G / \tau_{\mathrm{f}}\right)}
$$

This format was selected because it closely matches the $\tau / \tau_{\mathrm{f}}$ against $w / w_{\mathrm{f}}$ load-transfer curve recommended in API (2011) and ISO 19901-4 (ISO, 2020), as shown in Fig. 2(a). The adoption of the normalised format implies that the operational shear stiffness of the sand mass adjacent to the pile is assumed to vary directly with the ultimate shaft friction $\left(\tau_{\mathrm{f}}\right)$. In line with observations of load-transfer in sands, a post-peak strain-softening component is not required.

\section{Base load-transfer function $\left(\mathrm{q}_{b}-\mathrm{w}_{b}\right)$}

The base stress-base displacement $\left(q_{\mathrm{b}}-w_{\mathrm{b}}\right)$ response is also dependent on the non-linear and non-uniform stiffness of the sand in the vicinity of the pile base operating after the disturbance due to the pile driving. As for shaft friction, a simple normalised format is adopted here, for which a unique dependence of $q_{\mathrm{b}} / q_{\mathrm{b} 0 \cdot 1}$ with $w_{\mathrm{b}} / D$ is assumed. Reliable base stiffness data for driven piles are sparse largely due to the need to re-zero strain gauges after installation due to zero shifts in the strain gauges caused by pile driving. Data on driven pipe piles are particularly sparse due to the need to employ a strain-gauged twinwalled pile to enable separation of the relative contributions of the base plug load, annular resistance and external friction (e.g. Han et al., 2020).

The available base responses measured in tests included in the unified database are plotted in Fig. 3; all of these piles were closed-ended. It is seen that $q_{\mathrm{b}} / q_{\mathrm{b} 0 \cdot 1}$ against $w_{\mathrm{b}} / D$ variations are generally similar when $w_{\mathrm{b}} / D$ ratios exceed $1-2 \%$. The best-estimate trend line is shown in Fig. 3, which is also constrained by the requirement for $q_{\mathrm{b}} / q_{\mathrm{b} 0 \cdot 1}$ to be unity at $w_{\mathrm{b}} / D=0 \cdot 1$, begins from a $q_{\mathrm{b}} / q_{\mathrm{b} 0 \cdot 1}$ ratio equal to zero but gives a very stiff initial response, which can allow indirectly for the presence of residual base load, such as measured at Drammen. This trend line is described by the following hyperbolic equation:

$$
\frac{w_{\mathrm{b}}}{D}=0.01\left[\frac{q_{\mathrm{b}} / q_{\mathrm{b} 0 \cdot 1}}{1-0.9\left(q_{\mathrm{b}} / q_{\mathrm{b} 0 \cdot 1}\right)}\right]
$$

Equation (2) is employed together with the equation for $q_{\mathrm{b} 0 \cdot 1}$ given in Table 2 to represent the contribution of the base stiffness to the pile load-displacements curves. This equation implies that, in the same sand profile, the base stiffness of a large diameter open-ended pipe pile is only
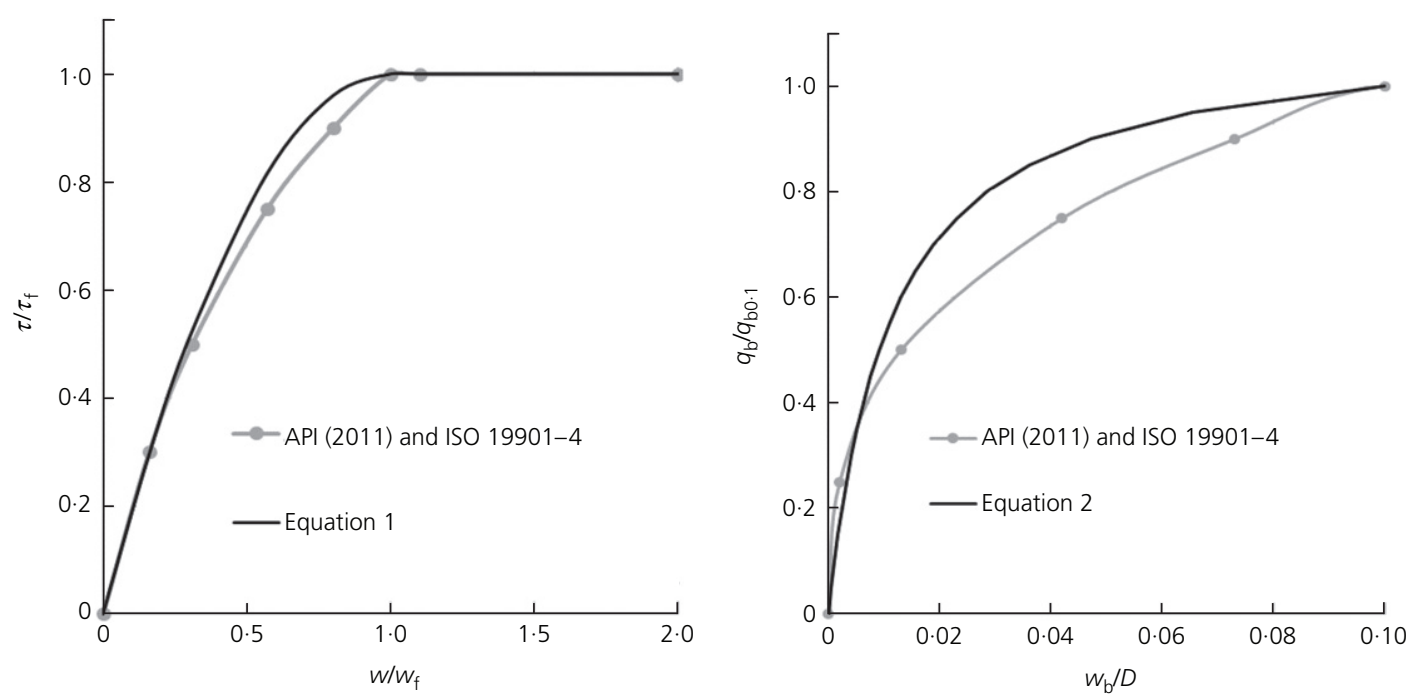

Fig. 2. Normalised pile load-transfer curves for shaft and base 


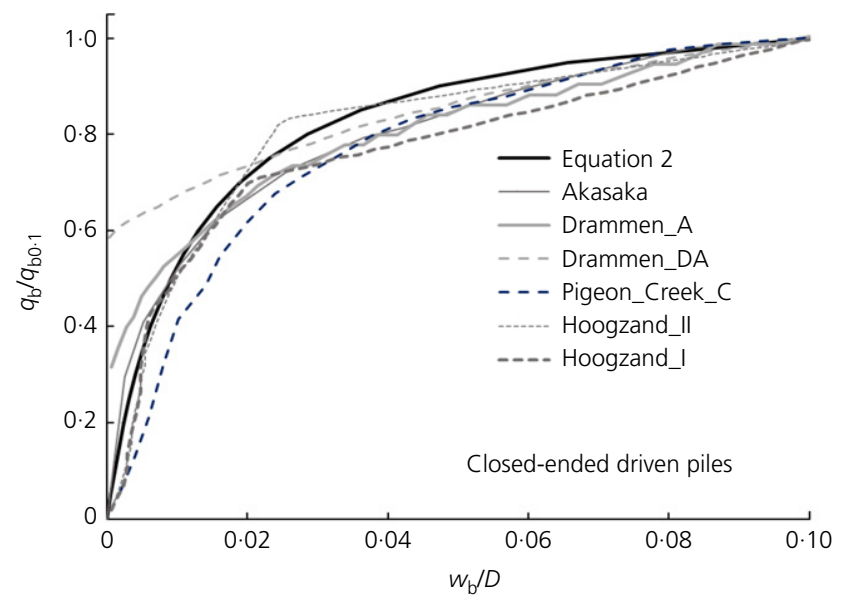

Fig. 3. Measured normalised base responses for closed-ended driven piles

about $25 \%$ of that of an equivalent closed-ended pipe pile (as the respective $q_{\mathrm{b} 0 \cdot 1}$ values differ by a factor of 4 ). Some justification for a proportional relationship between base stiffness and and $q_{\mathrm{b} 0 \cdot 1}$ as well as the general format of equation (2) are provided by Gavin \& Lehane (2007), although further studies are required.

It is seen in Fig. 2(b) that while equation (2) matches the ISO 19901-4 (ISO, 2020) and API (2011) recommendations for $q_{\mathrm{b}} / q_{\mathrm{b} 0 \cdot 1}$ up to $0 \cdot 4$, at larger base stresses, these recommendations predict greater base displacements than equation (2) - for example the $w_{\mathrm{b}}$ value at $q_{\mathrm{b}} / q_{\mathrm{b} 0 \cdot 1}=0.8$ is $60 \%$ higher than that given by this equation. Analyses using the procedures outlined below showed that the difference between both formats has a negligible influence on calculated displacements at typical working loads $\left(Q \leq 0.5 Q_{\mathrm{ult}}\right)$ when a higher proportion of the resistance is provided in shaft friction.

\section{CALIBRATED VALUES OF $W_{\mathrm{F}} / D$ FOR DATABASE PILES}

The pile head load-displacement $\left(Q-\delta_{\mathrm{h}}\right)$ responses exhibited by the database test piles were compared with those calculated using the RATZ program (Randolph, 2003). This program is one of many commercially available 'loadtransfer' programs that represent the pile as a series of one-dimensional elastic elements and the soil as a series of non-linear $\tau-w$ (or $t-z$ ) curves along the pile shaft with a $q_{\mathrm{b}}-$ $w_{\mathrm{b}}$ curve at the pile base.

The piles were sub-divided into 20 elements, each with an associated $\tau-w$ spring. Values of $q_{\mathrm{c}}$ and hence $\tau_{\mathrm{f}}$ were determined for each spring using the new unified CPT method (Table 2). The $q_{\mathrm{b} 0 \cdot 1}$ values were also determined from the same CPT method to enable the $q_{\mathrm{b}}-w_{\mathrm{b}}$ spring to be calculated. To ensure compliance with equation (2), an iterative approach for the base response was applied owing to limitations in the range of the $q_{\mathrm{b}}-w_{\mathrm{b}}$ curves that can be input to RATZ. The only soil variable remaining required for prediction of a $Q-\delta_{\mathrm{h}}$ response is the $G / \tau_{\mathrm{f}}$ ratio $\left(=4 D / w_{\mathrm{f}}\right)$ in equation (1). Two preliminary exercises assisted with establishing a correlation for this ratio:

(a) An initial set of calculations conducted for the tension piles in the database indicated $G / \tau_{\mathrm{f}}$ values $\left(=4 D / w_{\mathrm{f}}\right)$ required to match pile displacements at $50 \%$ of the ultimate capacity reduced systematically as the $q_{\mathrm{c}}$ value increased and the vertical effective stress $\left(\sigma_{\mathrm{v}}^{\prime}\right)$ increased. The trend may be anticipated considering the proportional relationship between $\tau_{\mathrm{f}}$ and $q_{\mathrm{c}}$ (ignoring the $\Delta \sigma_{\text {rd }}^{\prime}$ component of resistance; see Table 2) and a dependence of the maximum in situ shear modulus in sands $\left(G_{\max }\right)$ on $q_{\mathrm{c}}^{0 \cdot 33}$ and $\sigma_{\mathrm{v}}^{0 \cdot 33}$ (e.g. Schnaid et al., 2004).

(b) The pile database includes tension and compression tests on identical piles in the same soil at four sites (see Lehane et al., 2017). These tests showed that development of maximum shaft friction $\left(\tau_{\mathrm{f}}\right)$ in tension required displacements that were, on average, twice those required for development of $\tau_{\mathrm{f}}$ in compression piles - that is the $G / \tau_{\mathrm{f}}$ operating in compression is double the value for tension tests. This factor of 2 was incorporated in the determination of best-fit values of the $G / \tau_{\mathrm{f}}\left(=4 D / w_{\mathrm{f}}\right)$ ratio for the full database.

Correlations were explored that would minimise the difference between the measured and calculated $Q-\delta_{\mathrm{h}}$ responses of the database piles for loads that were less than $50 \%$ of the ultimate capacity $\left(Q_{\text {ult }}\right)$ - that is within the typical working range. The following relationship for the normalised displacement to peak shear $\left(w_{\mathrm{f}} / D\right)$ was found to provide a good fit to a large majority of the database (where $p_{\mathrm{a}}$ is the atmospheric pressure $=100 \mathrm{kPa}$ ):

$$
\begin{aligned}
\frac{w_{\mathrm{f}}}{D} & =\frac{q_{\mathrm{c}}^{0.5} \sigma_{\mathrm{v}}^{\prime 0 \cdot 25}}{A p_{\mathrm{a}}^{0.75}} A=1250(\text { compression }) ; A \\
& =625(\text { tension })
\end{aligned}
$$

Sand relative density $\left(D_{\mathrm{r}}\right)$ varies with the normalised CPT end resistance, $q_{\mathrm{c} 1 \mathrm{~N}}=q_{\mathrm{c}} /\left(p_{\mathrm{a}} \sigma_{\mathrm{v}}^{\prime}\right)^{0.5}$. Assuming $q_{\mathrm{c} 1 \mathrm{~N}}$ values of 70 and 220, which correspond approximately with sand relative densities $\left(D_{\mathrm{r}}\right)$ of 40 and $80 \%$, respectively (e.g. see Jamiolkowski et al., 2003), equation (3) leads to the variations of $w_{\mathrm{f}} / D$ as indicated in Fig. 4. As expected from equation (3), the $w_{\mathrm{f}} / D$ values in tension are seen to be twice those in compression. The values of $w_{\mathrm{f}} / D$ also vary significantly with the stress level and $D_{\mathrm{r}}$ value, approximately doubling with a two-fold increase in $D_{\mathrm{r}}$ and also increasing by a factor of 2 when the depth (or stress level) increases by 16 .

The values of $w_{\mathrm{f}} / D$ shown in Fig. 4 for database piles tested in compression (with an average pile length of $20 \mathrm{~m}$ and hence mean $\sigma_{\mathrm{v}}^{\prime}$ value of about $200 \mathrm{kPa}$ ) are generally in

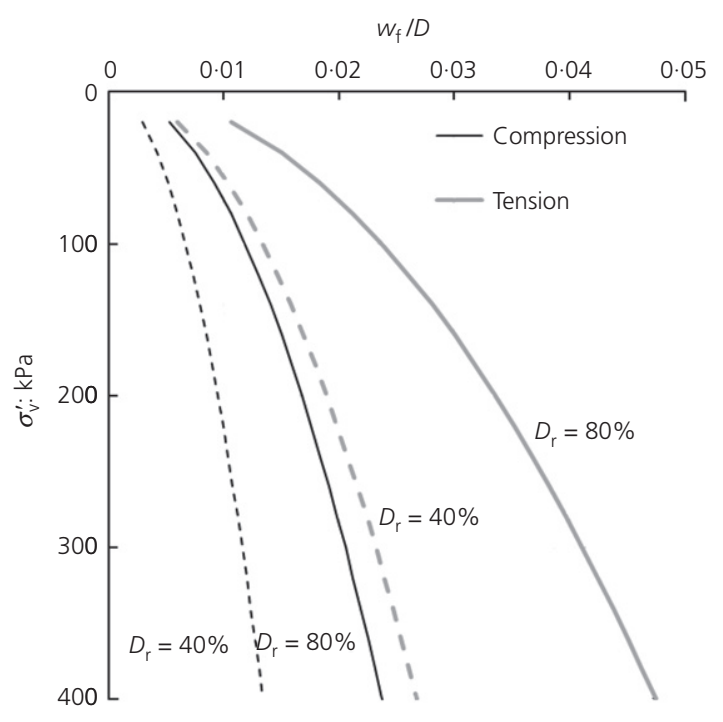

Fig. 4. Variation of $w_{\mathrm{f}} / D$ with $D_{\mathrm{r}}, \sigma_{\mathrm{v}}^{\prime}$ and loading direction implied by equation (2) 
line with those proposed by API (2011) which recommends a mean value of $0 \cdot 01$ for routine design purposes.

\section{Comparison of measured and calculated load- displacement curves}

The measured $Q-\delta_{\mathrm{h}}$ values for a representative selection of pile tests from the database are compared in Fig. 5 with the corresponding responses determined by RATZ using equations (1)-(3) combined with the formulations from the unified CPT method (Table 2) and the structural axial stiffness of the test piles. As for the initial calibration, the soil along each pile shaft was discretised into 20 soil horizons (i.e. springs) for which the average $\tau_{\mathrm{f}}$ was first calculated.

It is seen in Fig. 5 that the measured and calculated responses are in close agreement and particularly so, when the ultimate capacity (as given by the unified CPT method) matches the measured capacity. The difference between measured pile head displacement $\left(\delta_{\mathrm{hm}}\right)$ and calculated head displacement $\left(\delta_{\text {hc }}\right)$ is quantified in Fig. 6 at a pile head load of $50 \%$ of the ultimate capacity $\left(Q=0.5 Q_{\mathrm{ult}}\right)$. It is seen that the error in prediction is generally less than $0.5 \%$ of the pile diameter (e.g. about $2.5 \mathrm{~mm}$ for a typical database pile with a diameter of $500 \mathrm{~mm}$ ) for all closed-ended and open-ended piles tested in compression and tension.
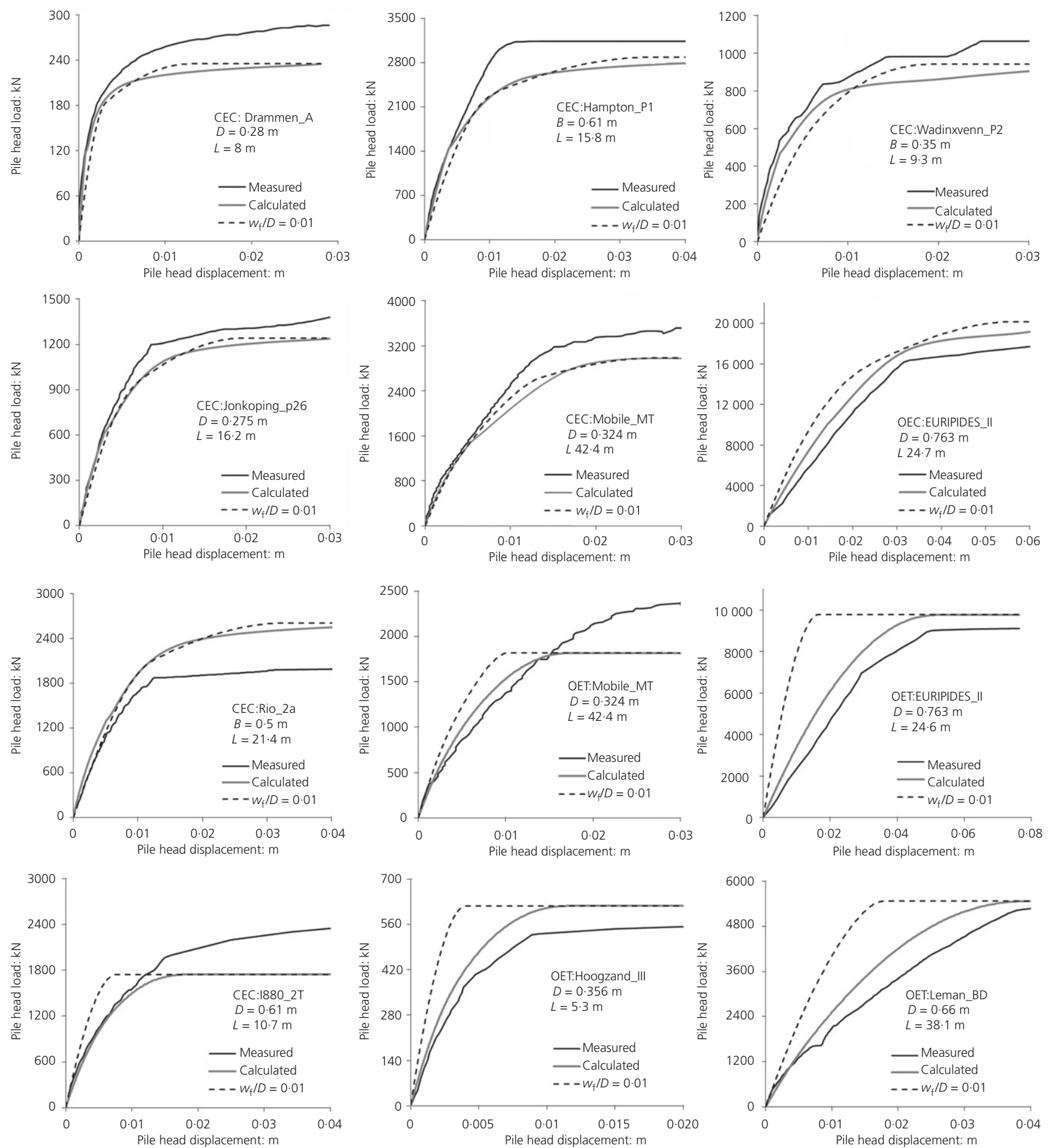

Fig. 5. Measured and calculated load-displacement responses for 16 pile tests in the unified sand database; see Table 1 for notation of pile type 

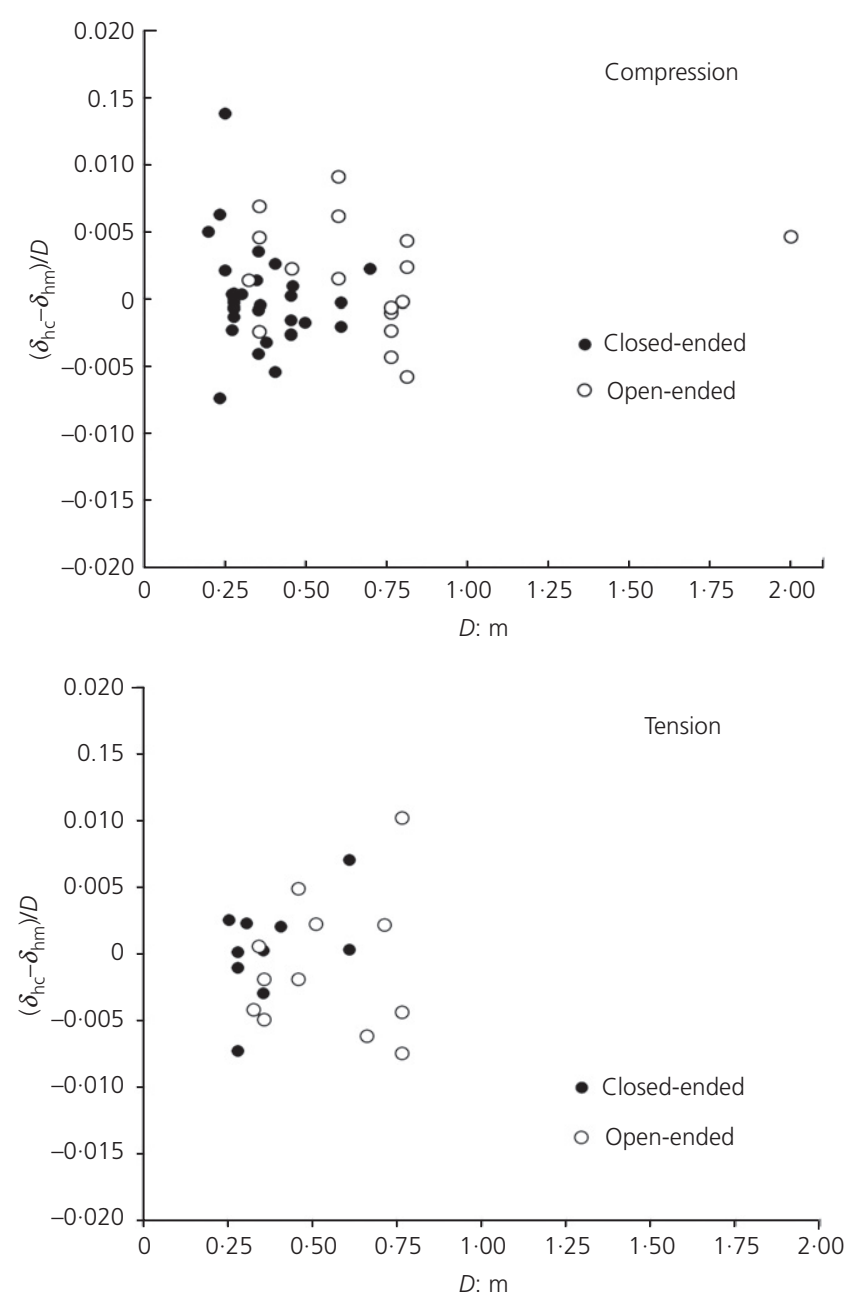

Fig. 6. Normalised differences between measured and calculated pile head displacements $\left(\delta_{\mathrm{h}}-\delta_{\mathrm{m}}\right) / D$ at $Q=0.5 Q_{\text {ult }}$ for driven piles in compression and tension

The calculated responses are compared with those predicted using the 'typical' $w_{\mathrm{f}} / D$ value of $0.01 \mathrm{rec}-$ ommended by API (2011) together with normalised $\tau-w$ and $q_{\mathrm{b}}-w_{\mathrm{b}}$ curves shown in Fig. 2 (but noting equation (2) was adopted for the base response). This comparison shows that the API (2011) recommendation is generally reasonable for many compression database piles. However, the assumption leads to an under-estimate of pile settlement in denser sands and for longer piles and a significant under-estimate of pile displacement for almost all piles tested in tension. With adoption of a constant $w_{\mathrm{f}} / D$ of $0 \cdot 01$, the predicted pile head displacements of the database piles at $Q=0 \cdot 5 Q_{\mathrm{ult}}$ are, on average, $0.002 D$ higher than measured for compression piles and $0.005 D$ lower for tension piles. Although these differences may be acceptable for short onshore piles (typical of the database), Fig. 4 indicates that significant overpredictions of pile axial stiffness can be expected for typical long offshore piles in dense sand and hence the use of equation (3) is preferable to the assumption of a constant $w_{\mathrm{f}} / D$ value.

\section{CONCLUSIONS}

A high-quality database of static load tests was employed to determine a simple CPT-based method to estimate the loaddisplacement response of driven piles in sand. It is shown that the use of equations (1)-(3) combined with the ultimate frictions and end bearing determined from the unified CPT method (Lehane et al., 2020, ISO 19901-4 (ISO, 2020)) may be used in a standard load-transfer program (e.g. RATZ, Randolph, 2003) to predict displacements to an expected accuracy of better than 0.005 times the pile diameter. The analyses show that the normalised displacement at which peak shaft friction is mobilised increases with sand relative density and depth and, for tension piles, is approximately double the value required for a compression pile.

\section{ACKNOWLEDGEMENTS}

The authors acknowledge the contributions of the NGI, particularly Dr Farrokh Nadim and Dr Suzanne Lacasse, for leading the two JIPs that led to the creation of the unified database of driven pile load tests and to the development of the unified CPT method for driven piles in sand, both of which were employed for this paper. The input of the team of experts to these JIPs, namely Professor Richard Jardine, Dr Philippe Jeanjean, Mr Bas van Dijk, Dr Mike Rattley and $\mathrm{Mr}$ Pasquale Carotenuto is gratefully appreciated. The initial JIP was sponsored by Equinor AS, Lundin Norway AS, Ørsted, DNVGL AS, ONGC and Petrobras. These sponsors were joined by BP, Total, ExxonMobil, EnBW, EDF, Aramco, SSER and Powerchina Huadong for the following JIP. The third author is supported by an Australian Postgraduate Award at UWA.

\section{REFERENCES}

API (2011). ANSI/API RP 2GEO: Geotechnical and foundation design considerations. ISO 19901-4:2003 (modified), Petroleum and natural gas industries-specific requirements for offshore structures, Part 4 - Geotechnical and foundation design considerations. 1st edn. Washington, DC, USA: API Publishing Services.

Boulanger, R. W. W. \& DeJong, J. T. T. (2018). Inverse filtering procedure to correct cone penetration data for thin-layer and transition effects. Cone penetration testing 2018: proceedings of the 4th international symposium on cone penetration testing (CPT'18) Delft, The Netherlands (eds M. A. Hicks, F. Pisanò and J. Peuchen), pp. 25-44. Boca Raton, FL, USA: CRC Press.

Chin, F. K. (1970). Estimation of the ultimate load of piles from tests not carried to failure. In Proceedings of the 2nd southeast asian conference on soil engineering, Singapore, pp. 81-90. Klong Luang, Thailand: Southeast Asian Society of Soil Engineering.

Coyle, H. M. \& Reese, L. C. (1966). Load transfer for axially loaded piles in clay. J. Soil Mech. Found. Div. 92, No. 2, 1-26.

Fellenius, B. H. (2018). Discussion of axial pile load transfer curves based on instrumented load tests. J. Geotech. Geoenv. Engng 144, No. 4, 07018005.

Gavin, K. \& Lehane, B. M. (2007). Base load-displacement response of piles in sand. Can. Geotech. J. 44, No. 9, 1053-1063.

Gwizdala, K. (1996). The analysis of pile settlements employing load-transfer functions. Tech University of Gdansk, Gdansk, Poland, Zesz. Nauk., PG Nr. 532, Budownictwo Wodne Nr. 41 (in Polish).

Han, F., Ganju, E., Prezzi, M., Salgado, R. \& Zaheer, M. (2020). Axial resistance of open-ended pipe pile driven in gravelly sand. Géotechnique 70, No. 2, 138-152, https://doi.org/10.1680/ jgeot.18.P.117.

ISO (International Organization for Standardization) (2020). 19901-4: Petroleum and natural gas industries - specific requirements for offshore structures. Part 4: Geotechnical and foundation design considerations. Geneva, Switzerland: International Standards Organisation (in press).

Jamiolkowski, M., Lo Presti, D. C. F. \& Manassero, M. (2003). Evaluation of relative density and shear strength of sands from CPT and DMT. In Soil behavior and soft ground construction (eds J. T. Germaine, T. C. Sheahan and R. V. Whitman), vol. 119, pp. 201-238. Reston, VA, USA: American Society of Civil Engineers. 
Lehane, B. M., Lim, J. K., Carotenuto, P., Nadim, F., Lacasse, S., Jardine, R. J. \& Van Dijk, B. F. J. (2017). Characteristics of unified databases for driven piles. In Proceedings of the 8th international conference on offshore site investigations and geotechnics (OSIG 2017), London, UK (eds M. D. J. Sayer, G. Griffiths and L. J. Ayling), vol. 1, pp. 162-191. London, UK: Society for Underwater Technology.

Lehane, B. M., Liu, Z. Bittar, E., Nadim, F., Lacasse, S., Jardine, R. J., Carotenuto, P., Jeanjean, P., Rattley, M., Gavin, K., Gilbert, R., Haavik, J. \& Morgan, N. (2020). A new CPT-based axial pile capacity design method for driven piles in sand. In 4th International symposium on frontiers in offshore geotechnics, ISFOG 21, Austin, TX, USA (ed. Z. Westgate), Paper number 3457. Austin, TX, USA: Deep Foundation Institute

Nadim, F., Lacasse, S., Liu, Z. \& Lehane, B. M. (2020). Improving the reliability of the calculated axial capacity of driven piles in sand. In 4th International symposium on frontiers in offshore geotechnics, ISFOG 21, Austin, TX, USA (ed. Z. Westgate), Paper number 3433. Austin, TX, USA: Deep Foundation Institute.

Randolph, M. F. (2003). Ratz version 4-2: load transfer analysis of axially loaded piles. School of Engineering, University of Western Australia, Perth, Australia.

Schmertmann, J. H. (1978). Guidelines for cone test, performance and design, FHWATS-78209. Washington, DC, USA: U.S Federal Highway Administration.

Schnaid, F., Lehane, B. M. \& Fahey, M. (2004). In-situ characterisation of geomaterials. In In-situ characterisation on geomaterials (eds A. V. Da Fonseca and P. W. Mayne), pp. 49-73. Porto, Portugal: Millpress Science.

Van der Veen, C. (1953). The bearing capacity of piles. Proceedings of the 3rd international conference soil mechanics and foundation engineering, Zürich, Switzerland, vol. 2, pp. 84-90. Zurich, Switzerland: Organizing Committee of ICSMFE.

\section{HOW CAN YOU CONTRIBUTE?}

To discuss this paper, please submit up to 500 words to the editor at journals@ice.org.uk. Your contribution will be forwarded to the author(s) for a reply and, if considered appropriate by the editorial board, it will be published as a discussion in a future issue of the journal. 